\title{
KONJAKU MONOGATARISHÛ: SUMÔ E OS LUTADORES ${ }^{1}$ KONJAKU MONOGATARISHÛ: SUMO AND THE WRESTLERS
}

\section{Luiza Nana Yoshida}

RESUMO: O sumô é atualmente uma modalidade de luta bastante popular no Japão, cuja origem remonta aos tempos antigos e a referência ao sumô é encontrada em Kojiki e Nihonshoki, obras do século VIII. Em Konjaku Monogatarishû, as narrativas sobre sumô destacam-se não só por apresentar a figura do lutador de sumô, completamente contrastante com as personagens representativas da literatura de Heian, como também por retratarem os detalhes da competição como a luta entre a força e a técnica, bem como o sentimento dos lutadores e dos espectadores. Palavras-Chave: Konjaku Monogatarishû; Narrativas setsuwa; Sumô; Força descomunal

ABSTRACT: Sumo is currently a very popular fighting modality in Japan which origin dates back to ancient times, and reference to sumo is found in Kojiki and Nihonshoki works from the 8th century. In Konjaku Monogatarishû the narratives about sumo stand out not only for presenting the figure of the sumo wrestler, completely contrasting with typical characters of Heian Literature, but also for portraying the details of the competition as the struggle between strength and technique as well as the feeling of wrestlers and spectators.

Keywords: Konjaku Monogatarishû; Setsuwa narratives; Sumo; Overwhelming strength

\section{INTRODUÇÃO}

O presente trabalho pretende abordar as narrativas sobre sumô 相撲 incluídas na obra Konjaku Monogatarishû今昔物語集, coletânea de narrativas denominadas setsuwa 説話 do século XII. As narrativas a serem analisadas encontram-se inseridas no tomo XXIII que enfoca principalmente o tema da força descomunal.

1 Artigo submetido em 6/10/2020 e aceito em 14/11/2020.

2 Doutorado em Letras (Teoria Literária e Literatura Comparada) pela Universidade de São Paulo. Professora Sênior da Área de Japonês da Faculdade de Filosofia, Letras e Ciências Humanas da Universidade de São Paulo; nanayo@usp.br; (ORCID iD: https://orcid.org/0000-0001-7535-0636). 
O objetivo principal é o de elaborar um breve histórico do Sumai no Sechi ${ }^{3}$, Festival Anual de Sumô, um evento sazonal do sétimo mês realizado no palácio com a presença do imperador, nas épocas Nara e Heian ${ }^{4}$, bem como destacar o caráter inovador do lutador de sumô como uma personagem na literatura da época. O sumô teria originalmente surgido como um bailado cujos movimentos vigorosos buscavam afastar os espíritos que causavam males e aterrorizavam a vida da comunidade, tornando-se, posteriormente, uma luta baseada na medida de forças ${ }^{5}$. O sumô fazia parte também dos eventos religiosos relacionados à agricultura, e na época do imperador Shômu ${ }^{6}$ foi incluído entre os eventos anuais da corte imperial. Na época Heian, já se apresentava muito mais como um evento de entretenimento, perdendo seu significado divino original ${ }^{7}$. Trata-se de um dos poucos eventos anuais da corte de caráter nacional, no sentido de que lutadores de várias províncias reuniam-se na $\mathrm{Capital}^{8}$ para a disputa.

\section{ORIGEM E PRIMÓRDIOS DO SUMÔ}

A História da origem do sumô é longa e complexa, datada de milhares de anos atrás. Assim, não será o objetivo deste trabalho fazer a explanação minuciosa de sua origem e desenvolvimento, mas fazer breves referências aos registros mais antigos.

Atualmente, a palavra sumô é utilizada para indicar o ôzumô, sumô profissional promovido pela Associação Japonesa de Sumô. Trata-se de um combate corpo a corpo travado entre dois lutadores. Posicionados no centro de um ringue circular de terra batida, delimitado por sacos de palha com terra, e construído sobre uma plataforma quadrada, é considerado vencedor aquele que conseguir derrubar o adversário ou colocá-lo para fora do ringue. Não se conhece a época exata do estabelecimento do ringue, mas passa a ser citado e retratado em documentos e ilustrações do final do século XVII ${ }^{9}$.

Quanto ao traje, os lutadores usam atualmente uma espécie de faix ${ }^{10}$ enrolada na cintura, cobrindo e protegendo a parte íntima do lutador. Conforme observações

3 Sumai no Sechi 相撲節 - denominado também Sumai no Sechie 相撲節会 ou Sechie Zumô 節会相撲 teria se desenvolvido para o sumô atual.

4 Época Nara, Nara Jidai 奈良時代 e época Heian, Heian Jidai 平安時代 - abrangem, respectivamente o período de 710 a 794 e de 794 a 1192.

5 Cf. YAMADA, Tomoko. Sechie Zumôkô. $<$ https://echolab.ddo.jp/Libraries/大谷学報64巻第2/大谷 学報64巻第2号003山田知子「節会相撲孝」.pdf>

6 Imperador Shômu 聖武天皇 - reinou de 724 a 749.

7 Cf. Komine (org.), 2003, p. 64.

8 O termo "Capital" em maiúscula foi utilizado para indicar a capital Heiankyô.

9 Cf. Nitta, 1994, p. 205-207.

10 A faixa ou mawashi 迴し possui normalmente $6 \mathrm{~m}$ de comprimento por $45 \mathrm{~cm}$ de largura. 
de Nagano Jôichi1 ${ }^{11}$, o traje usado pelos lutadores na época do Sumai no Sechi era uma espécie de tanga denominada tôsaki ou tôsagi ${ }^{12}$.

Com relação à etimologia e a grafia do termo sumô, recorreu-se ao estudo de Nitta (1994), segundo o qual o termo sumô é a substantivação de sumai, forma flexionada de sumau cujo significado é "lutar, disputar". Sumai é, portanto, a forma antiga da qual derivam os termos sumaibito, "pessoa que luta sumô" e Sumai no Sechi(e) $)^{13}$, "Evento Anual de Sumô". Não se sabe a época exata em que o termo passou a ser pronunciado sumô, mas em documentos como Nippojisho ${ }^{14}$ e Gizankôkaku ${ }^{15}$, já existe o registro da pronúncia sumô. Quanto às grafias, as comumente utilizadas são 相撲 $\mathrm{e}$ 角力, originalmente expressões chinesas, que possuíam sentido de "lutar um contra o outro" ou "medir forças", e atualmente são utilizadas com a leitura "sumô", que é um ateji $i^{16}$. Nitta observa ainda que a denominação de "lutador de sumô" Antiguidade, a denominação usual era sumaibito 相撲人 ou simplesmente sumai 相撲, utilização comum na época Chûsei ${ }^{18}$. No final da época Chûsei, surge o termo sumôtori 相撲取り, que se difunde na época Kinsei ${ }^{19}$. A denominação rikishi 力士, utilizada nos dias atuais, indicava originalmente "homem de força extraordinária" e parece ter sido adotada a partir da época Kinsei.

Sabe-se que a existência de lutas corpo a corpo é antiga, confirmada através da descoberta de objetos ou pinturas de homens em combate. Nas ruínas da antiga Babilônia, por exemplo, foram encontradas figuras de homens em posição de luta, datadas de 5 mil anos atrás, e no Egito foram descobertos desenhos em pinturas murais nas ruínas de Beni $\operatorname{Hasan}^{20}$.

11 NAGANO, J. Konjaku Monogatarishû no Kanshô to Hihyô. Tokyo, Meiji Shoin, 1978, p. 136-138.

12 Tôsaki ou tôsagi 浴衣 - tipo de tanga semelhante ao atual fundoshi 褌. Segundo observação dos organizadores da Coleção Nihon Koten Bungaku Zenshû da Editora Shôgakukan, o termo tôsaki aparece em Konjaku Monogatarish $\hat{u}$ com a grafia 俗衣, mas a grafia correta seria 浴衣.

13 Sumaibito e Sumai no Sechie(e) são grafados, respectivamente 相撲人 e 相撲節 (会) em japonês.

14 Nippojisho 日葡辞書, dicionário Japonês-Português, publicado pela Companhia de Jesus, em 1603.

15 Gizakôkaku 義残後覚, uma coletânea de miscelâneas de 1596, de autoria de Guken 愚軒.

16 Ateji 当て字 - leitura japonesa do caractere chinês baseada não no significado, mas apenas no uso fonético.

17 A transformação da denominação "lutador de sumô” em japonês: sumaibito 相撲人, sumai 相撲, sumôtori 相撲取り, rikishi 力士.

18 Época Chûsei, Chûsei Jidai 中世時代 - corresponde à Idade Média Japonesa e abrange o período de 1192 a 1573.

19 Época Kinsei, Kinsei Jidai 近世時代 - época Pré-Moderna que abrange o período de 1573 a 1868.

20 Cf. WAKAYAMA, Moritarô. Sumô Ima Mukashi. Tokyo, Kawade Shobô Shinsha, 1963, p. 12. 
Ainda segundo Nitta, quanto a documentos arqueológicos e históricos sobre o sumô encontrados no Japão, a terracota haniwa ${ }^{21}$ encontrada no túmulo $k o f u n^{22}$ de Inbe Hachimanyama, na cidade de Wakayama, é uma das mais conhecidas, no Japão. O haniwa encontrado neste túmulo, datado do início do século VI, é a figura de um lutador, trajando apenas um tipo de tanga denominado fundoshi, com os joelhos levemente dobrados e com os braços esticados para a frente. $\mathrm{Na}$ área da arqueologia, a figura de um haniwa "nu com fundoshi" ${ }^{23}$ é um dos índices para a certificação de que se trata da figura de um lutador. É uma característica semelhante à encontrada na figura de lutadores das pinturas murais do Complexo de Túmulos kofun de Goguryeo ${ }^{24}$, dos séculos IV a VI, ou nas descrições de lutas chinesas encontradas em documentos históricos, atestando a influência das lutas desses países na formação do sumô, conforme citado por autores como Nitta Ichirô (2016) e P. L. Cuyler (1979) em seus estudos sobre o sumô.

No Japão, os registros mitológicos e históricos mais antigos sobre o que poderia ser a origem do sumô podem ser encontrados nas obras Kojiki ${ }^{25}$ (Registro de Fatos Antigos), de 712, e Nihonshoki ${ }^{26}$ (Registro sobre o Japão), de 720. Em Kojiki, encontra-se a mitologia sobre a "Cessão do País" ${ }^{27}$, episódio em que Ôkunishi no Mikoto ${ }^{28}$ cede o país de Ashihara no Nakatsukuni ${ }^{29}$ para Ninigi no Mikoto ${ }^{30}$, cumprindo a ordem da

21 Haniwa 埴輪 - são figuras de terracota encontradas nos túmulos antigos denominados kofun. Foram encontradas, entre outras, figuras humanas, de animais, de utensílios domésticos.

22 Kofun 古墳 - túmulos antigos e gigantescos construídos para imperadores ou pessoas de alta hierarquia, surgidos entre os séculos III a VII.

23 “Nu com fundoshi” ou rashin ni fundoshi 裸身に褌.

24 Um dos reinos que formavam a atual Coreia na época dos Três Reinados (século 1 a.C. - século 7 d.C). Os três reinados eram formados por Goguryeo ou Kôkuri 高句麗 (século I a.C. - 668), Baekje ou Kudara 百済 (século IV - 660) e Silla ou Shiragi 新羅 (século IV - 935).

25 Kojiki 古事記 - a mais antiga crônica histórica japonesa foi registrada por Ô no Yasumaro 太安麻呂 (723-?), baseado na memorização da genealogia imperial e documentos antigos feita por Hieda no Are 稗田阿礼, sob a ordem do imperador Tenmu 天武 (673-686). Narra o nascimento e a formação do Estado japonês, abarcando até a época da imperatriz Suiko 推古 (592-628).

26 Nihonshoki 日本書紀 - uma das seis crônicas históricas do Japão compiladas sob a ordem imperial. Relata cronologicamente a mitologia, as tradições e registros históricos, desde a Idade dos Deuses até a época do imperador Jitô 持統 (690-697).

27 “Cessão do país” - em japonês kuniyuzuri 国譲り.

28 Ôkuninushi no Mikoto 大国主命 - deus que administrava o Mundo dos Homens.

29 Ashihara no Nakatsukuni 芦原中津国 - antiga denominação do Japão utilizada em Kojiki e Nihonshoki. Refere-se ao Mundo dos Homens que ficava entre o Mundo Celestial, Takamagahara 高天原, reino de Amaterasu, e o Reino da Escuridão, Yomi no Kuni 黄泉の国.

30 Ninigi no Mikoto 雨邇芸命 - neto de Amaterasu foi por ela designado para governar o Mundo dos Homens. 
deusa Amaterasu Ômikami ${ }^{31}$. A deusa Amaterasu envia Takemikazuchi no Kami ${ }^{32}$ como emissário e, diante da resistência de Takeminakata no Kami ${ }^{33}$, filho de Ôkuninushi, os dois deuses travam uma disputa na localidade de Izumo ${ }^{34}$, "medindo suas forças ${ }^{35}$." Takeminakata, após ser derrotado por Takemikazuchi, foge para a região de Suwa ${ }^{36}$, na província de Shinano ${ }^{37}$.

O registro mais antigo sobre a luta travada entre dois homens é encontrado em Nihonshoki, cujo episódio relata a disputa de forças entre Nomi no Sukune ${ }^{38}$ (visto atualmente como ancestral e deus do sumô), considerado o homem mais forte do país de Izumo, e Taima no Kehaya, do país de Yamato ${ }^{39}$, que se gabava de ser o homem mais forte do país. Convocados pelo imperador $\operatorname{Suinin}^{40}$ para se enfrentarem, no sétimo mês do ano 7 da era Suinin (ano 23 a.C.), a disputa é vencida por Sukune, que fratura as costelas de Kehaya com um chute e com um outro lhe esmaga o quadril, matando-o. Assim, Sukune recebe do imperador as terras de Kehaya e passa a ser servidor imperial, sendo considerado fundador do clã Haji, responsável pelos enterros, pela construção dos túmulos kofun ou pela fabricação de artefatos de argila. Diz-se que a substituição pelas terracotas haniwa dos homens que se imolavam para serem enterrados junto com o imperador nos túmulos kofun ocorreu por influência de Sukune.

$\mathrm{Na}$ formação do sumô, coexistem questões de diversas naturezas, o que permite o estudo do sumô não apenas como uma luta de "medida de forças", mas através de sua relação com rituais religiosos, eventos sazonais da corte, como entretenimento, ou a sua profissionalização como esporte.

As lutas registradas tanto em Kojiki quanto em Nihonshoki demonstram um estágio ainda em desenvolvimento e não possuem todas as características do sumô que se conhece hoje em dia, mas podem ser vistas como suas formas primordiais.

31 Amaterasu Ômikami 天照大神 - Deusa-do-Sol, é filha de Izanagi, deus fundador do Japão juntamente com sua esposa Izanami. Amaterasu é a deusa soberana do Mundo Celestial, e considerada ancestral da família imperial japonesa.

32 Takemikazuchi no Kami 建御雷神 - emissário enviado por Amaterasu para Izumo.

33 Takeminakata no Kami 建御名方主神 - filho de Ôkuninushi no Mikoto.

34 Izumo 出雲 - corresponde à parte sul da atual província de Shimane.

35 Cf. Idem, ibidem, p. 13. "Medir forças" consistia basicamente no fato de os lutadores segurarem-se pelas mãos e tentarem derrubar o adversário.

36 Suwa 須羽 - atual cidade de Suwa 諏訪.

37 Shinano 科野 - atual província de Nagano 長野.

38 Nomi no Sukune 野見宿禰 e Taima no Kehaya 当麻蹴速 - considerados precursores dos lutadores de sumô.

39 Yamato 大和 - corresponde à atual província de Nara 奈良.

40 Imperador Suinin 垂仁 - $11^{\circ}$. imperador que teria reinado de 29 a.C. a 70. 


\section{O FESTIVAL ANUAL SUMAI NO SECHI ${ }^{41}$}

Conforme explanado anteriormente, o sumô (ou os primórdios do sumô) era realizado desde os tempos antigos, mas não existem documentos que comprovem a origem do evento anual Sumai no Sechi, que teria se iniciado no século VIII e, no século IX, incluído entre os eventos anuais da corte, tendo continuidade até o final do século XII, ou seja, por toda a época Heian.

Existem várias referências sobre o sumô nas crônicas históricas, sendo a mais antiga a existente em Nihonshoki, onde se vê o registro de que em 642, no primeiro ano do reinado da imperatriz Kôgyoku ${ }^{42}$, houve uma luta de sumô entre os guardas do palácio, por ocasião da visita do emissário de Kudara. Já em Shokunihongi ${ }^{43}$ (Registro sobre o Japão - Continuação), encontra-se o registro daquilo que pode indicar a fase inicial do sistema que administra o Sumai no Sechi. Consta no registro que, no quarto dia do sétimo mês do terceiro ano da era Yôrô ${ }^{44}$ (719), ocorreu pela primeira vez a nomeação de nukide no tsukasa, uma espécie de antecessor do sumai no tsukasa ${ }^{45}$, organizador do Sumai no Sechi. Diz ainda a mesma crônica que, no sétimo dia do sétimo mês do sexto ano da era Tenpyô ${ }^{46}(734)$, o imperador Shômu ${ }^{47}$ assistiu a uma luta de sumô, fato considerado como um dos primeiros registros da realização do Sumai no Sechi.

Conforme Nitta (1994), a origem do Sumai no Sechi como um evento anual da corte encontra-se relacionada principalmente a dois aspectos: o ritual agrícola e o ritual de subordinação ${ }^{48}$.

Segundo os estudos folclóricos, a origem do sumô e também de outras atividades de caráter competitivo como o cabo de guerra, tsunahiki, ou a competição de cavalo, kurabeuma, provêm de antigas cerimônias e ritos de adivinhação, denominados

41 Os dados referentes a Sumai no Sechi foram baseados principalmente nos trabalhos de CUYLER, P. L. (1979), NITTA, Ichirô (1994) e WAKAMORI, Tarô (1963).

42 Imperatriz Kôgyoku 皇極天皇 - reinou de 642 a 645 e voltou a ocupar o trono como imperatriz Saimei 斉明天皇 de 655 a 661 .

43 Shokunihogi 続日本紀 - uma das seis crônicas históricas oficiais do Japão. Dando continuidade a Nihonshoki, registra cronologicamente o período que abrange o reinado do imperador Monmu 文武 天皇 $(697$ - 707) até o imperador Kanmu 桓武天皇 $(781$ - 806).

44 Era Yôrô 養老 - período de 717 a 724 .

45 Nukide no tsukasa 抜出司 e sumai no tsukasa 相撲司- referem-se ao funcionários encarregados de organizar o Sumai no Sechi.

46 Era Tenpyô 天平 - período de 729 a 749.

47 Imperador Shômu 聖武天皇 - reinou de 724 a 749. Fervoroso seguidor do Budismo, construiu o templo Tôdai-ji 東大寺, em Nara, onde se encontra a estátua do Grande Buda.

48 Referem-se, respectivamente, a nôkô girei 農耕儀礼 e fukuzoku girei 服属儀礼. 
toshiura ${ }^{49}$. Tratava-se ao mesmo tempo de uma celebração aos antepassados e a realização de adivinhação ligada à colheita, cuja safra seria farta ou ruim conforme o resultado das competições. No caso específico do sumô, destaca-se a sua relação com os rituais relacionados à divindade do arrozal ou espírito da água ${ }^{50}$, a divindade que controla a boa ou a má colheita. Naturalmente, a celebração da adivinhação pode apresentar variações conforme a região, mas dentre os sumô praticados atualmente, pode-se citar, por exemplo, o "sumô na lama ${ }^{51}$ ", onde se acreditava que haveria mais sorte quanto mais os lutadores ficassem sujos de lama, ou o "sumô do choro ${ }^{52}$ ", em que bebês carregados por lutadores de sumô são colocados frente a frente e se considera vencedor o lado que o bebê chorar primeiro. Cabe lembrar que a criança, devido à sua condição de um ser ainda em formação, era considerada mais próxima do mundo dos espíritos e fazia muitas vezes o papel de intermediário das divindades nas cerimônias de adivinhação. Sabe-se também que, no período inicial do Sumai no Sechi, era realizado o sumô de crianças que antecedia as lutas principais ${ }^{53}$.

Os episódios encontrados em Kojiki e Nihonshoki relativos às lutas entre os deuses Takemikazuchi e Takeminakata e entre Sukune e Kehaya, citados anteriormente, possuem como motivos comuns o fato de um "homem forte vindo de longe, ou seja, um marebito $^{54}$, subjugar o homem forte ou o mau espírito local, tornando-se súdito imperial ${ }^{55 "}$ ". Esses episódios são considerados a representação do "ritual da subordinação". Trata-se de um motivo que tem em sua base os motivos relativos à divindade da água e expressa a conquista empreendida por um forasteiro e a sua posterior subordinação ao imperador. Pode-se dizer que "o significado primordial do Sumai no Sechi foi o fato de reconfirmar a estruturação domínio - subordinação, recriando esses motivos como um evento nacional. ${ }^{56 "}$

Segundo o pesquisador Obinata Katsumi ${ }^{57}$, o Sumai no Sechi que se estabeleceu como um evento anual da corte por quase 400 anos, sofreu uma grande mudança em

49 Cabo de guerra, competição de cavalo e ritos de adivinhação correspondem, respectivamente, a tsu$n a h i k i$ 綱引き, kurabeuma 競馬 e toshiura 年占 em japonês.

50 Divindade do arrozal e espírito da água, ta no kami 田の神 e mizu no seirei 水の精霊 em japonês.

51 Sumô na lama, doronkozumô よ゙ろんこ相撲 em japonês.

52 Sumô do choro, nakizumô 泣き相撲 em japonês.

53 O sumô de crianças que antecedia as lutas principais era denominado urate 占手.

54 Termo utilizado por Orikuchi Shinobu 折口信夫 (1887-1953) para indicar o "forasteiro com talento extraordinário" proveniente de um mundo distante, tokoyo no kuni 常世の国, nas crenças e tradições populares japonesas.

55 Cf. NITTA, Ichirô. Sumô no Rekishi. Tokyo, Yamakawa Shuppansha, 1994, p. 73.

56 Cf. NITTA, Ichirô. Sumô no Rekishi. Tokyo, Yamakawa Shuppansha, 1994, p. 74

57 Cf. OBINATA, Katsumi 大日方克己. Kodai Kokka to Nenjû Gyôji (Eventos Anuais da Antiguidade). Tokyo, Yoshikawa Kôbunkan, 1993. Apud NITTA, Ichirô. Sumô no Rekishi. Tokyo, Yamakawa Shuppansha, 1994, p. 81. 
seu conteúdo e caráter como um rito nacional, por volta do século IX. Nitta (1994) faz um trabalho de reconstituição de como seria o Sumai no Sechi baseado em livros sobre Cerimônias da Corte Japonesa, como Dairishiki ${ }^{58}$ e Gishiki $i^{59}$. A estruturação que constitui a base do Sumai no Sechi parece estar no fato de concentrar as forças dos homens mais fortes do país e oferecê-las ao imperador. P. L. Cuyler (1991), ao falar sobre as influências das lutas asiáticas nas origens do sumô, observa que existem registros sobre lutas na China que datam da dinastia Chou ( $\cong 1030-221$ a.C.). Por volta do século $X$, as lutas eram conhecidas como chiao-ti ou chiao-li e grafadas 角力, que literalmente significa "força do chifre". Originalmente o chiao-ti se referia a competições ritualísticas nas festividades rurais, quando homens usando chapéus com chifres praticavam uma luta semelhante a uma dança denominada ch'ih yu-hsi. Com o aperfeiçoamento das técnicas de luta, o chiao-ti passou a ser praticado nos treinamentos militares da guarda imperial, juntamente com o manejo de arco e flecha e a condução da carruagem de guerra. Posteriormente, aquilo que era um treinamento bélico tornou-se um entretenimento da corte na China ${ }^{60}$. Conforme observa Nitta (1994), Cuyler acredita que o modelo original do Sumai no Sechi como uma cerimônia de subordinação dos homens fortes das províncias teria sido introduzido da China, observando que uma competição de artes marciais realizada com a convocação de lutadores do país todo como uma cerimônia simbólica de unificação do país poderia ser considerada como um tipo de ritual de subordinação. Complementando, Nitta enfatiza o fato de que a influência da cultura chinesa nas cerimônias da corte japonesa não se restringe ao Sumai no Sechi, mas a outros eventos anuais.

\section{OS LUTADORES DE SUMAI NO SECHI EM KONJAKU MONOGATARISHÛ}

As narrativas voltadas para o tema do sumô podem ser encontradas dispersas em vários tomos de Konjaku Monogatarish û, mas no tomo XXIII encontra-se um agrupamento delas (narrativas 21 a 25). Apesar de o sumô ter uma origem antiga, conforme explanado anteriormente, Konjaku Monogatarish $\hat{u}$ foi a primeira obra a fazer uma compilação de narrativas relativas ao tema, destacando lutadores renomados e seus feitos ou fracassos.

A narrativa 21/ Sobre o fato de os estudantes do Setor de Altos Estudos enfrentarem o lutador de sumô Narimura ${ }^{61}$ aborda o confronto ocorrido entre um grupo de lutadores

58 Dairishiki 内裏式 (Cerimônias do Palácio Imperial) - concluído em 821, foi o primeiro livro oficial sobre a interpretação das Cerimônias Palacianas, organizado sob a ordem do imperador Saga 嵯峨天皇.

59 Gishiki 儀式 (Cerimônias) - livro sobre a regulamentação dos procedimentos cerimoniais da Corte, organizado e revisado diversas vezes, após o século VIII.

60 Cf. CUYLER, P. L. Sumo - From Rite to Sport. 3a. reimpressão, New York\&Tokyo, Weatherhill, 1991.

61 A mesma narrativa, com pequenas modificações, encontra-se inserida em Uji Shûi Monogatari 宇治 拾遺物語, uma coletânea de narrativas setsuwa do século XIII com o título "Sobre o fato de Narimura encontrar-se com um estudante de força descomunal”, narrativa 13 do tomo II. 
de sumô e os estudantes do Setor de Altos Estudos ${ }^{62}$, na época do Sumai no Sechi, que era realizado nos finais do sétimo mês como um dos eventos anuais da corte.

Segundo Nagano Jôichi ${ }^{63}$ a administração do Sumai no Sechi estava a cargo do Ministério de Assuntos Militares ${ }^{64}$, e os funcionários do Quartel da Guarda da Residência Imperial da Direita e da Esquerda ${ }^{65}$ eram responsáveis por recrutar e supervisionar os lutadores, bem como dar-lhes assistência enquanto permanecessem na Capital. Os lutadores selecionados chegavam na Capital um mês antes da cerimônia para os preparativos e eram divididos em dois grupos, o da Direita e o da Esquerda (o número de lutadores parece variar conforme a época, tendo em média 30 lutadores de cada lado ${ }^{66}$ ) conforme a Divisão que representavam. Dois dias antes do evento, fazia-se o treino ${ }^{67}$ dentro de cada grupo, e no dia da cerimônia propriamente dita, ocorria o confronto entre os lutadores dos dois grupos ${ }^{68}$, e no dia seguinte, realizavam-se o confronto seletivo ${ }^{69}$ entre os vencedores do dia anterior, e a luta eliminatória ${ }^{70}$. A partir do século IX, as lutas passaram a ser realizadas no interior do palácio imperial em locais como o jardim sul do Salão Cerimonial ${ }^{71}$, e a elas assistiam o imperador, os membros da família imperial e um público seleto de servidores. Os lutadores mais fortes de cada grupo eram chamados de hote $^{72}$, seguidos pelos hotewaki $i^{73}$.

O Setor de Altos Estudos ficava situado em frente ao Portal Suzaku (ou Shujaku), entrada principal do Palácio Imperial, localizado ao sul do palácio, e na principal avenida

62 Refere-se a Daigakuryô 大学寮, uma instituição de estudo superior para a formação de burocratas, estabelecida conforme o Sistema Ritsuryô.

63 NAGANO, Jôichi. Konjaku Monogatarishû no Kanshô to Hihyô. Tokyo, Meiji Shoin, 1978, p.103-104.

64 Ministério dos Assuntos Militares, Hyôbushô 兵部省 - um dos oito Ministérios estabelecidos pelo Sistema Ritsuryô.

65 Quartel da Guarda da Residência Imperial da Direita e da Esquerda, Saukonoefu 左右近衛府 - Konoefu é um órgão governamental externo ao código administrativo do Sistema Ritsuryô responsável pela segurança da residência imperial. Havia o Quartel da Divisão da Esquerda e da Direita cuja denominação era baseada no modelo chinês, não havendo qualquer implicação geográfica, política ou ideológica.

66 Cf. Nagano, 1978, p. 124.

67 Em japonês, uchidori 内取り.

68 Em japonês, meshiawase 召し合わせ.

69 Em japonês, nukide 抜出.

70 Em japonês, oisumai 追相撲.

71 Refere-se a Shishinden 紫宸殿, principal edifício cerimonial da residência imperial.

72 Hote 最手 - o grau mais alto. Equivale ao atual ôzeki 大関, um grau abaixo do grande campeão, yokozuna 横綱.

73 Hotewaki 最手脇 - o segundo grau mais alto. Equivale ao atual sekiwake 関脇. 
de mesmo nome, Suzaku Ôji ${ }^{74}$. Tratava-se de um importante órgão formador dos futuros burocratas do governo central e provincial. O Código Yôrô75 estabeleceu, no século VIII, o Setor de Altos Estudos na Capital e, nas províncias, as Escolas Provinciais, onde estudavam, respectivamente, os filhos da alta ou média nobreza e os filhos dos potentados locais. Eram ministrados diversos estudos, sendo os básicos as Crônicas Históricas e Poemas Chineses, Estudo das Leis, Estudo dos Clássicos Chineses, Matemática, além de Fonética Chinesa e Caligrafia ${ }^{76}$, ministrados por especialistas de cada área, denominados hakase ${ }^{77}$.

A narrativa 21 ocorre nos dias que antecedem o Sumai no Sechi e abre-se com a apresentação do lutador Makami no Narimura ${ }^{78}$, pai de Makami no Tamemura ${ }^{79}$ e avô de Tsunenori ${ }^{80}$ e lutador veterano da província de Michi no $\mathrm{Oku}^{81}$. Tudo indica tratar-se de um lutador conhecido e de uma família tradicionalmente ligada ao sumô.

Quanto aos estudantes do Setor de Altos Estudos, há o destaque de um deles, de estatura baixa e mais bem trajado que os demais.

O contraste da posição social entre os lutadores e os estudantes é referido através dos próprios trajes. Narimura, lutador de sumô recrutado na Província, vestia um "traje cotidiano $^{82} \mathrm{com}$ a gola aberta e o chapéu laqueado ${ }^{83}$ enfiado $^{84}$ na cabeça" onde se percebe uma informalidade e até um certo desleixo (lutadores oriundos das províncias), e o

74 Suzaku Ôji 朱雀大路 - refere-se à Avenida Suzaku que divide Heiankyô em Capital da Direita (Ukyô 右京) e Capital da Esquerda (Sakyô 左京), e vai do Portal Suzaku até o Portal Rajômon (ou Rashômon) 羅生門 localizado no extremo sul da Capital.

75 Código Yôrô, Yôrô Ritsuryô 養老律令 - código de leis em 10 tomos, implementado em 757.

76 Correspondem, respectivamente, a Kiden 紀伝, Myôhô 明法, Myôgyô 明経, San 算, On 音 e Sho 書.

77 Hakase 博士 - na época Heian, refere-se a especialistas de determinada área de estudo. Não era um título acadêmico (cf. hakase ou hakushi), mas um cargo público.

78 Makami no Narimura 真髪成村一 em Nichûreki 二中暦, dicionário do início da época Kamakura (1192-1333), aparece com a grafia 真井, mas a grafia correta seria 真甘 que juntamente com 真上 e 真 髪 (esta última utilizada na narrativa), podem ser lidas Makami. Era lutador da época do imperador En'yû e conforme a Narrativa XXIII/25, sua última aparição na Capital foi em 984, e teria sido morto dez anos depois. Cf. SAKAKURA, Atsuyoshi e outros. Konjaku Monogatarishû - Honchô Sezokubu Ichi. Coleção Shinchô Nihon Koten Shûsei. Tokyo, Shinchôsha, 1978, nota 3, p. 82.

79 Makami no Tamemura 真髪為村 - em Shôyûki 小右記, diário de Fujiwara no Sanesuke 藤原実資, consta que Narimura era o pai de Tamenari 為成. (Cf. Mabuchi, Kazuo e outros (1974), nota 36, p. 265)

80 Tsunenori 経則 - identidade imprecisa.

81 Michi no Oku 奥州, Michinoku ou Mutsu 陸奥 ou Ôshû 奥州 englobava parte das atuais províncias do nordeste: Aomori 青森, Iwate 岩手, Miyazaki 宮崎 e Fukushima 福島. Na narrativa 25 do mesmo tomo, consta que Narimura seria da província de Hitachi 常陸, atual província de Ibaraki 茨城.

82 Refere-se a suikan shôzoku 水干装束, traje cotidiano usado pela povo em geral.

83 Refere-se a eboshi 烏帽子, chapéu utilizado pelos homens no dia a dia.

84 Em japonês, oshiire 押入, denotando que o chapéu fora colocado sem cuidado. 
estudante, um futuro burocrata da elite, com um chapéu e túnica formais ${ }^{85}$ (representante da Capital).

Os estudantes da Capital veem-se incomodados pelos modos provincianos dos lutadores (o vozerio) e impedem-lhes a passagem defronte ao Setor de Altos Estudos, onde estudam. Naquele momento, os lutadores acham por bem não forçar e recuam diante dos estudantes da elite. O resultado do confronto, minuciosamente planejado pelos lutadores para o dia seguinte, parece estar óbvio: lutadores de sumô selecionados contra estudantes liderados por um jovem com desvantagem física.

O estudante, no entanto, surpreende pela sua força descomunal (levanta um dos lutadores como se fosse uma fina bengala e avança em direção ao grupo) e agilidade. Narimura é perseguido pelo estudante e, quando tentava pular um muro, o estudante agarra-o pelo calcanhar e lhe arranca o calçado juntamente com a pele que se desprende como se tivesse sido retalhado com uma espada. O surgimento desse estudante de aparência frágil, mas possuidor de uma força incomum que põe o seleto grupo de lutadores para correr, coloca em evidência uma das características das narrativas setsuwa que reside no fato de trazer acontecimentos que contrariam o óbvio, causando uma inversão da ordem e, nesse caso, uma desordem, visto que o desfalque de importantes lutadores deve ter afetado o brilhantismo do Sumai no Sechi daquele ano.

Outro fato que chama a atenção é a parte final da narrativa em que se vê Narimura relatando aos funcionários do Quartel da Guarda da Residência Imperial que o estudante poderia ser um lutador de sumô sem igual. Estes, por sua vez, relatam ao imperador que lança uma ordem de busca pelo estudante, expressando desta forma a importância do evento, cuja realização acaba por envolver até mesmo a figura do imperador. A narrativa fecha-se com a permanência do mistério, visto o desaparecimento do estudante, cuja identidade nunca foi conhecida.

A narrativa 25/ Sobre o combate entre os lutadores de sumô Narimura e Tsuneyo aborda uma luta entre os lutadores mais fortes do grupo da Esquerda e da Direita, denominados hote, durante o Sumai no Sechi ocorrido no sétimo mês de 984, na época do imperador En'yû ${ }^{86}$.

Conforme citado anteriormente, o Sumai no Sechi se estende por dois dias e a narrativa relata o confronto seletivo realizado no segundo dia entre Makami no Narimura, hote da Esquerda da província de Hitachi, e Ama no Tsuneyo ${ }^{87}$, hote da Direita da província de Tango ${ }^{88}$. Os dois lutadores estavam em atividade desde o reinado do imperador

85 Referem-se, respectivamente, a kanmuri 冠, o chapéu formal e a ue no kinu 表衣, túnica formal masculina, de mangas largas e gola redonda.

86 O imperador En’yû, En'yû tennô 円融天皇, foi o 64‥ Imperador, reinou no período de 969-984. É filho do imperador Murakami, Murakami tennô 村上 天皇, $62^{\circ}$. Imperador, que reinou de 946-967 e conhecido por tentar realizar um governo direto.

87 Ama no Tsuneyo 海ノ常世 - identidade desconhecida. Na narrativa 22, seu nome é grafado 恒世.

88 Província de Tango 丹後, atual parte norte de Kyoto 京都. 
Murakami, pai do imperador En'yû, sendo Makami mais antigo e Tsuneyo mais novo. Segundo Nagano Jôichi, era comum que muitos lutadores, ao alcançarem a posição de hote, conseguissem assegurar a posição sem a necessidade de lutar efetivamente, o que explicaria a presença de alguns lutadores com mais de 50 anos. E quando se viam obrigados a lutar, utilizavam-se do recurso do "impedimento ${ }^{89 ", ~ p o r ~ m o t i v o s ~ d e ~ s a u ́ d e, ~}$ lesão, ficando desobrigados de competir ${ }^{90}$.

Pode-se dizer que a luta entre Narimura e Tsuneyo seria um "duelo de gigantes" aguardado com muita expectativa. Conhecendo-se e respeitando-se há muito tempo, qualquer que fosse o resultado, causaria um grande abalo a ambos. No caso de Narimura, por estar no mundo do sumô há mais tempo que Tsuneyo, a derrota provavelmente seria desoladora. Essa tensão que precede a luta fica evidente na atitude tomada por Narimura, que por sete vezes solicita o impedimento para suspender o confronto, mas não é atendido. Sem alternativa, só restou a Narimura enfrentar Tsuneyo. Contrastando com a tensão inicial, a luta é descrita de forma bastante dinâmica, minuciosa e objetiva:

Narimura, aos prantos, pede o impedimento pela sétima vez, mas diante da recusa, levanta-se furioso e, aproximando-se alucinadamente do adversário, agarra-se a ele. Tsuneyo segura o pescoço de Narimura com um dos braços e com o outro tenta segurá-lo na região da axila. Narimura puxa a parte dianteira do tôsagi e o segura pelos lados. Pressionando seu peito contra o de Tsuneyo, agarra-o desesperadamente, puxa-o com toda força, surpreendendo Tsuneyo que lhe sussurra: "Estais louco? O que pretendeis?" Narimura, no entanto, parecia não escutá-lo e puxava-o fortemente, tentando enganchar sua perna na de Tsuneyo pela parte externa ${ }^{91}$. Tsuneyo, no entanto, reverteu a situação e enroscou sua perna pela parte interna da perna de Narimura ${ }^{92}$, e jogou todo o seu peso sobre ele que tombou de costas. Tsuneyo desabou de lado sobre ele.

Segundo Magara Hiroshi ${ }^{93}$, em Kojiki há episódios sobre lutas que podem ser consideradas origens do sumô, e a obra Konjaku Monogatarish $\hat{u}$ seria provavelmente a primeira a descrever um tipo de golpe muito semelhante ao que é denominado atualmente como kawazugake ${ }^{94}$, e destaca parte da narrativa onde se encontra incluído o trecho

89 Sawari môshi 障り申し em japonês.

90 Cf. NAGANO, Jôichi. Konjaku Monogatarishû no Kanshô to Hihyô. Tokyo, Meiji Shoin, 1978, p. 125.

91 É um golpe que tenta imobilizar a perna do adversário, travando-a pelo lado externo. É um golpe denominado atualmente como sotogake 外掛け, “travar pelo lado externo”.

92 Golpe que tenta imobilizar e derrubar o oponente, enroscando a perna pela parte interna da perna do adversário e conhecido atualmente como uchigake 内掛け, “travar pelo lado interno".

93 Cf. MAGARA, Hiroshi. Kawazugake ni tsuite. Disponível em <https://core.ac.uk/download/ pdf/59282438.pdf>

94 Kawazugake 河津掛 - o golpe teria sido utilizado na luta entre Kawazu Sukeyasu 河津祐保 e Matano Kagehisa 俣野景久, guerreiros da época Heian. Consiste em enroscar uma das pernas na parte interna 
acima. No sumô, o kawazukake é um golpe pouco utilizado nos dias de hoje, e no judô, sua prática é proibida devido ao risco de ferir gravemente o adversário.

Narimura e Tsuneyo tombam diante de um público estarrecido e segue-se um momento de silêncio no lugar da costumeira euforia do grupo vencedor. Narimura consegue se levantar, mas Tsuneyo permanece caído e é retirado com a ajuda dos encarregados do evento. O que se segue após essa histórica luta constitui um dos inúmeros dramas ocultos por trás de um dos grandes eventos imperiais e resulta numa contenda onde não existem vencedores, visto que ambos ficam incapacitados de lutar: Narimura retorna para a sua província e nunca mais volta à Capital, corroído pela vergonha, e Tsuneyo, apesar da vitória, fica gravemente ferido e falece pouco tempo depois. O que se sobressai é a total indiferença dos organizadores diante da condição de Tsuneyo, e eufóricos, são incapazes de perceber o seu grave estado, e só pensam em recompensá-lo, oferecendo-lhe prêmios.

Desde então, a luta entre os hote do grupo da Esquerda e da Direita passou a ser considerada de mau agouro e, foi abolida ${ }^{95}$, pois as pessoas passaram a relacionar o ocorrido com a abdicação do imperador que se deu no oitavo mês do ano da realização do evento. Isso é contestado pelo narrador ${ }^{96}$, que alega ser essa superstição decorrente do desconhecimento da verdade dos fatos. A narrativa fecha-se, dizendo que, apesar disso, a realização da luta entre Narimura e Tsuneyo continuou a ser duramente criticada.

As narrativas 22/ Sobre o fato de o lutador de sumô Ama no Tsuneyo enfrentar uma serpente e 23/ Sobre o fato de o lutador de sumô Kisaichi no Munehira levantar um tubarão e atirá-lo para longe narram episódios ocorridos com os lutadores em suas respectivas províncias, sem relação, portanto, com o evento da Cerimônia do Sumai no Sechi, porém enfatizam a força descomunal dos lutadores fora dos ringues, ao enfrentarem e vencerem, sem qualquer dificuldade, uma serpente gigante e um terrível tubarão.

A primeira narrativa inicia-se com a apresentação da personagem inserida num cenário de tranquilidade, à sombra de uma árvore, na beira de um rio próximo à sua casa, buscando fugir do calor sufocante do verão. Tsuneyo, já citado anteriormente, faz um passeio descontraído, tendo como companhia apenas um menino e encontra-se trajado conforme o clima e a ocasião: um quimono sem forro ${ }^{97}$ amarrado com uma faixa na altura do quadril, calçando um tamanco de madeira com salto ${ }^{98}$ e usando uma bengala com a extremidade bifurcada.

da perna do adversário e com um dos braços segurar o pescoço e derrubá-lo de costas. Uma das cenas mais conhecidas do kawazugake é a encontrada na pintura em rolo Chôjûgiga 鳥獣戯画, do século XII, que retrata a luta de sumô entre um sapo e um coelho.

95 Segundo MABUCHI e outros (1974), nota 39, p. 265, em Shôyûki 小右記 há registro da realização da luta entre os hote, mesmo após essa data.

96 Narrador ou katarite 語り手 - refere-se “àquele que conta ou transmite a história”

97 Refere-se a katabira 帷子, quimono sem forro usado no verão.

98 Refere-se a ashida 足駄, tipo de tamanco de madeira alto com saltos ( $h a$ 歯, “dente”). 
Nas narrativas setsuwa, o rio simboliza muitas vezes o limite entre dois mundos e sua presença adquire um papel de destaque nesse cenário, na medida em que é, nesse caso, a morada de uma serpente gigante que tenta arrastar Tsuneyo para lá. A profundidade abismal do rio cria um clima de mistério e tensão, enquanto se acompanha a lenta aproximação de Tsuneyo em direção ao rio: "próximo à casa onde Tsuneyo morava, havia um rio de aspecto envelhecido que possuía uma parte bem profunda...", "(Tsuneyo) foi para debaixo da árvore que ficava próximo a essa parte funda", "A parte funda era tenebrosa, de um verde escuro que não se via o fundo." O surgimento da serpente gigante é descrito de uma forma bastante detalhada e com certo clima de apreensão, prenunciando a luta que será travada entre Tsuneyo e a serpente:

Em pé, (Tsuneyo) olhava o rio tomado pela vegetação (...), quando viu a superfície da água se erguer e vir em sua direção lá do outro lado da margem que ficava a cerca de nove metros da parte profunda. "Que será aquilo?”, pensava Tsuneyo, quando já perto da margem onde ele estava, surgiu a cabeça de uma enorme serpente. Enquanto Tsuneyo, ainda de pé, observa-a, pensando: "Pelo tamanho da cabeça, deve ser uma serpente enorme! Será que subirá para esta margem?", a serpente olhava fixamente para ele com a cabeça levantada. "O que aquela serpente pretende fazer comigo?", indagava-se Tsuneyo, enquanto observava-a imóvel, depois de se afastar cerca de 1,50 metros da margem. Depois de observá-lo fixamente durante um tempo, a serpente mergulhou a cabeça na água.

A cena descreve o confronto de olhares que antecede o combate físico. Pelo fato de tratar-se de uma luta entre um homem e um animal (que por si só possui uma força animalesca e aqui reforçada pela expressão "gigante") o resultado parece previsível. Cabe lembrar, no entanto, que a serpente não enfrentará um homem comum, mas um lutador de sumô, normalmente portador de uma força descomunal. A luta é descrita da seguinte forma:

Depois disso, ele notou uma onda levantar-se em direção à margem oposta, mas logo depois uma outra onda começou a se aproximar em sua direção. Em seguida, a serpente levantou sua cauda fora da água e virou em direção ao local onde Tsuneyo permanecia de pé. "Esta serpente deve ter algo em mente", pensou e deixou que ela agisse à vontade, ocasião em que a serpente esticou sua cauda e deu umas duas voltas na perna de Tsuneyo. Ele permaneceu imóvel, pensando: "O que será que ela pretende fazer?", quando a serpente enrolou-a bem firme e começou a arrastá-lo fortemente. "Ah, então ela pretende me arrastar para dentro da água!", percebeu, e fincou firmemente os pés no chão. Ao sentir que a serpente puxava-o com uma força extrema, os saltos do seu tamanco se quebraram. Sentiu que poderia cair, efincou os pés mais firmemente ainda, conseguindo permanecer em pé, mas era impossível descrever tamanha força e, vendo que era capaz de ser arrastado, firmou os pés tão fortemente que eles afundaram cerca de 15 a $18 \mathrm{~cm} \mathrm{na}$ terra dura. No instante em que pensou: "Que puxada espantosa!", sentiu a serpente partir-se repentinamente como uma corda e pareceu-lhe que o rio vertia sangue. Ao puxar a perna, deduzindo: "Deve ter se partido!", a cauda despedaçada da 
serpente foi arrastada para a margem. No mesmo instante, desenrolou a cauda e lavou a perna com água, mas a marca deixada pela cauda não desapareceu.

Essa cena em que Tsuneyo finca firmemente seus pés na terra dura e afunda-os faz lembrar o episódio do encontro entre a deusa Amaterasu Ômikami e seu irmão Susanoo no Mikoto99, em Kojiki. A cena é descrita assim: "(Amaterasu) pisa a terra dura, afundando suas pernas até suas coxas desaparecerem e finca seus pés firmemente ${ }^{100 ",}$, ao saber que seu irmão lhe faria uma visita, e temendo que ele pudesse lhe trazer problemas, preparou-se para enfrentá-lo, vestida como um guerreiro.

Susanoo, por sua vez, após causar uma grande desordem no reino de Amaterasu, é expulso do Mundo Celestial e enviado para o Mundo dos Homens onde enfrenta uma serpente de oito cabeças e oito caudas ${ }^{101}$ para salvar a vida de uma jovem que, posteriormente, irá se tornar sua esposa. O confronto e a vitória contra a serpente simbolizam o início da regeneração de Susanoo, deus que, desde o seu nascimento, se destacava principalmente pela sua rebeldia e violência, causando grande desgosto a Amaterasu. Com a vitória sobre a serpente, Susanoo mostra-se mais amadurecido, casa-se, forma a sua família e cuida do seu reino. Naturalmente, o contexto da narrativa setsuwa difere do contexto mitológico que se encontra baseado na força divina e heroica dos deuses Amaterasu e Susanoo, que possuem um papel de destaque na mitologia da criação do país. Mas, relacionando-se a figura do lutador de sumô ao motivo do marebito ${ }^{102}$, "forasteiro excepcional", citado por Orikuchi Shinobu, seria possível identificar Tsuneyo com um marebito, visto que os lutadores normalmente são "forasteiros" de força excepcional que, selecionados nas províncias, são convocados para lutarem na Capital, por ocasião do Sumai no Sechi. A força descomunal de Tsuneyo é exaltada não só por ter enfrentado uma serpente gigante, a ver pelo diâmetro do corte da cauda rompida que tinha cerca de $30 \mathrm{~cm}$, mas principalmente pelo seu poder físico capaz de partir em duas a serpente que possuía uma força equivalente a cerca de sessenta homens.

Pode-se dizer que justamente pelo fato de Tsuneyo ser apenas um ser humano e não um deus ou herói como Amaterasu e seu irmão Susanoo, mas ter sido capaz de praticar um feito tão extraordinário, seu nome restou para a História como um lutador de sumô, portador de uma força sobre-humana.

99 Susanoo no Mikoto 須佐之男命 - Deus-do-Mar, é irmão mais novo de Amaterasu. Devido ao seu temperamento voluntarioso, causou muitos desgostos a Amaterasu e foi expulso para o Mundo dos Homens onde se redimiu depois de vencer uma serpente gigante de oito cabeças e oito caudas.

100Cf. OGIHARA, Asao e KÔNOSU, Hayao (Revisão e anotações). "Amaterasu Ômikami to Susanoo no Mikoto". In: Kojiki.Jôdai Kayô. Coleção Nihon Koten Bungaku Zenshû 1. Tokyo, Shôgakukan, 1973, p. 75.

101 Referida em Kojiki e Nihonshoki, Yamata no Orochi 八岐大蛇 era uma serpente monstruosa de oito cabeças e oito caudas, que todos os anos surgia para alimentar-se de uma das oito filhas de um casal de velhos. Susanoo consegue matar a serpente e a filha caçula é salva, tornando-se sua esposa.

102 Cf. nota 51, p. 7. Mudança de página conforme a impressão. 
A narrativa 23/ Sobre o fato de o lutador de sumô Kisaichi no Munehira levantar um tubarão e atirá-lo para longe, assim como a anterior, trata da força descomunal de um lutador de sumô que enfrenta também uma criatura aquática, ou seja, os lutadores de sumô dessas narrativas, além de se destacarem como homens mais fortes do mundo terrestre, mostram-se invencíveis até diante de criaturas da água.

A narrativa abre-se, apresentando dois lutadores de sumô, Kisaichi no Munehira ${ }^{103}$ e Tomo no Setayo ${ }^{104}$, representantes do Quartel da Guarda da Residência Imperial da Esquerda. Munehira, da província de Suruga ${ }^{105}$, alcançou rapidamente o grau de waki, segundo grau mais alto entre os lutadores de sumô, vencendo todos os seus adversários, tanto do seu grupo como do outro, com seus habilidosos golpes. Setayo era do mesmo grupo de Munehira e era da província de Mikawa ${ }^{106}$. Possuía um corpo avantajado e era detentor do grau mais alto de hote, havia muito tempo. Perdeu, no entanto, seu título para Munehira, quando tiveram que se enfrentar.

A narrativa se desenvolve durante uma caçada, quando Munehira sai em perseguição de um veado ferido que tenta atravessar uma enseada, fugindo em direção à montanha que ficava do outro lado da margem. Mostrando-se um hábil nadador, Munehira consegue alcançar o veado que estava a cerca de 300 a 400 metros à frente, segura suas patas traseiras, carrega-o nas costas e nada de volta à margem de onde saíra. Nisso, uma onda branca se forma no alto mar e segue em direção a Munehira. Seus companheiros de caça alertam-no sobre a onda que teria sido causada provavelmente por um tubarão $0^{107}$.

$\mathrm{O}$ ataque do tubarão se repete por várias vezes e, cada vez que a onda cobria Munehira, as pessoas achavam que ele havia sido engolido pelo tubarão. No entanto, ele continuava a nadar em direção à margem, e quando faltavam cerca de 3 ou 6 metros da margem, Munehira carregava apenas as patas traseiras e os ossos da bacia do veado. Os momentos finais do ataque são descritos da seguinte maneira:

Quando a onda já estava bem próxima, o tubarão, com seus olhos cintilantes qual tigela de metal e sua monstruosa boca aberta com dentes afiadíssimos como a espada, aproximou-se, e estava prestes a abocanhar Munehira, mas no mesmo instante, este enfiou as patas do veado na boca do tubarão, passou a mão por baixo da mandibula inferior, curvou a cabeça, e, aos brados, arremessou o tubarão

103 Kisaichi no Munehira 私市宗平 - lutador em evidência na época do imperador Ichijô 一条天皇 (9861011). Há registros sobre a sua atuação como hote em diários de nobres como Gonki 権記, diário de Fujiwara no Yukinari 藤原行成, renomado calígrafo dos meados da época Heian e Shôyuki 小右記, diário de Fujiwara no Sanesuke 藤原実資, grande conhecedor de usos, práticas, cerimônias da Corte.

104 Tomo no Setayo伴勢田世 - lutador da época do imperador Ichijô, mas desconhece-se detalhes de sua vida. 105 Suruga 駿河 - refere-se à atual província de Shizuoka 静岡.

106 Mikawa 参河- refere-se à atual província de Aichi 愛知.

107 Em japonês, wani 鰐. Animal citado em diversas obras como Kojiki e Nihonshoki, existem controvérsias entre os estudiosos com relação ao que seria wani: crocodilo, tubarão (ou ainda dragão ou serpente do mar). 
para bem longe em direção à margem, como se estivesse atirando um lutador de sumô. Lançado em direção à terra firme a uma distância de cerca de 3 metros, o tubarão debatia-se desesperadamente e, segurando ainda as patas do veado na boca, foi morto a flechadas pelos arqueiros que estavam em terra.

Assim como Tsuneyo, que partiu uma serpente gigante em dois, Munehira demonstra sua força descomunal ao arremessar o tubarão para longe, utilizando-se de um golpe muito semelhante ao do sumô, provando sua superioridade de hote tanto na terra como na água ao vencer um animal aquático em seu próprio habitat. No caso de Munehira, soma-se à sua força, o conhecimento que possuía com relação aos costumes do tubarão, o que acaba por salvar sua vida. Segundo Munehira, o tubarão tem por hábito não se alimentar da caça no local, mas levá-la para os seus domínios e voltar para pegar o resto da caça, se houver. Assim, a cada ataque, Munehira fez com que o tubarão carregasse parte do veado: primeiro, a cabeça e o pescoço, depois, as patas dianteiras e o ventre, e, finalmente, as patas traseiras e ossos da bacia, ganhando tempo para nadar até a margem. Naturalmente, tal conhecimento seria inútil, caso Munehira não fosse um homem de força descomunal.

Apesar da controvérsia sobre o significado de wani, se seria tubarão ou crocodilo, optou-se no presente trabalho por "tubarão", pelo fato de o crocodilo não ser considerado um animal originário do Japão, e também por ter sido utilizado pelos organizadores da Coleção Nihon Koten Bungaku Zenshû, adotada como fonte do corpus das narrativas analisadas. Atualmente, a palavra wani significa "crocodilo", mas sabe-se que em determinadas regiões como na província de Tottori, na parte oeste da ilha principal e banhada pelo Mar do Japão, o tubarão é referido como wani.

A narrativa 24/ Sobre a força descomunal da irmã mais nova do lutador de sumô Ôi no Mitsutô relata sobre a força descomunal da irmã de um renomado lutador Ôi no Mitsutô ${ }^{108}$, da província de Kai109. Conforme a narrativa, Mitsutô era um lutador extraordinário do Quartel da Guarda da Residência Imperial da Esquerda, de estatura baixa, mas corpulento, forte e ágil. Sua irmã mais nova tinha cerca de 27 ou 28 anos e possuía belas feições.

Embora a narrativa não seja sobre Mitsutô, cuja fama como lutador fica evidente na sua apresentação, refere-se a um episódio singular que envolve sua vida familiar, dando a conhecer aspectos de sua vida pessoal.

Inicialmente, a narrativa chama a atenção por relatar o caso de sequestro de uma mulher que é mantida refém em sua casa por um fugitivo, sob a ameaça de uma espada. Ela era a irmã mais nova de Mitsutô e morava num anexo da casa do irmão. Alguém da casa presencia o sequestro e corre alvoroçado para avisar Mitsutô. Esperava-se,

108 Ôi no Mitsutô 大井光遠 - lutador da época do imperador Ichijô. Seu nome aparece em Zokuhonchô Ojôden 続本朝往生伝, coletânea de narrativas sobre os renascidos na Terra Pura, compilada por Ôe no Masafusa 大江匡房, entre 1001 e 1011.

109Kai 甲斐 - corresponde à atual província de Yamanashi 山梨. 
naturalmente, que ele saísse sem demora em socorro da irmã, mas ao saber que a irmã é mantida refém, Mitsutô não esboça qualquer reação, dizendo calmamente que o único que talvez fosse capaz de tomá-la como refém seria Ujinaga ${ }^{110}$, antigo lutador da província de Satsuma ${ }^{111}$. O contraste entre o desespero daquele que fora avisar Mitsutô e a tranquilidade deste prenuncia o inusitado desenrolar da ação.

Preocupado com o que estava acontecendo, a pessoa que presenciou o sequestro volta para o anexo da irmã de Mitsutô e espia pela fresta o interior, descrito da seguinte maneira:

....como estavam no nono mês, a mulher vestia apenas um fino quimono de algodão e cobria a boca com uma das mãos, enquanto com a outra segurava levemente o braço do homem que lhe apontava uma espada. O homem empunhava uma espada assustadora com a lâmina voltada para a mulher e, direcionando-a para o seu abdômen, estava sentado no chão com as pernas cruzadas, abraçando-a pelas costas. A jovem, então, com a mão direita, parecia segurar levemente o braço com o qual o homem lhe apontava a espada, e com a esquerda cobria seu rosto e parecia estar chorando, mas logo com a mesma mão começou a revolver as vinte ou trinta hastes de flecha de bambu desbastadas e espalhadas à sua frente; com os dedos pressionou os nós dos bambus contra o piso de madeira, esmigalhando-os como se fossem uma árvore apodrecida. Tanto o homem que foi alertar Mitsutô quanto o sequestrador assistiam a tudo, assombrados.

As mulheres da época costumavam cobrir a boca com a mão ou com a manga do quimono, quando se mostravam envergonhadas ou constrangidas diante de pessoas do sexo oposto. No caso da irmã de Mitsutô, o fato desse gesto tão tipicamente feminino ser destacado torna-se importante, pois evidencia sua aparente fragilidade (conforme palavras de Mitsutô, "ela tem a aparência frágil e feminina") cuja total transformação vai ocorrer no momento seguinte. Sem esboçar qualquer reação mais violenta, através apenas da demonstração de sua força descomunal, esmagando os bambus com a ponta de seus dedos, a irmã de Mitsutô torna-se uma figura estarrecedora, levando o sequestrador a fugir desesperadamente, deixando tudo para trás, temendo ser despedaçado. Perseguido, capturado e levado diante de Mitsutô, o sequestrador tem confirmado os seus temores, quando Mitsutô revela que a força de sua irmã supera em dobro a sua própria, tanto que, se ela lhe segurar fortemente o braço, mesmo que de brincadeira, seus dedos se abriam naturalmente pela pressão excessiva. Mitsutô diz ao sequestrador que ele tivera muita sorte por não ter sido esfacelado por ela. Completa dizendo que era uma grande pena ela ser uma mulher, pois se fosse um lutador de sumô, certamente não teria adversários à altura. Mitsutô acaba soltando o sequestrador, que foge apavorado ao ouvir que ela era

110 Refere-se provavelmente a Tomo no Ujinaga 伴の氏長, lutador considerado invencível, atuou na época do imperador Ninmyô 任明天皇 (reinado 833-850).

111 Corresponde a parte da atual província de Kagoshima 鹿児島. 
capaz de partir o chifre de um veado como se fosse um galho seco e que, portanto, não teria qualquer dificuldade em estraçalhá-lo.

A força descomunal da irmã de Mitsutô é medida através da capacidade de destruir bambus apenas com os dedos, não havendo necessidade de um ataque direto contra o sequestrador, e é exaustivamente confirmada como superior à sua pelo irmão, um lutador de sumô, categoria que reunia, à época, os homens mais fortes do país.

\section{CONSIDERAÇÕES FINAIS}

A coletânea Konjaku Monogatarishû foi compilada no final de Heian, época da derrocada da nobreza e do alvorecer dos guerreiros bushi. A literatura de Heian, em sua época áurea, era focada quase que totalmente no mundo da elite nobiliárquica que a produzia, refletindo seu estilo de vida baseado no refinamento, na elegância, na sensibilidade apurada conceitos associados à estética do mono no aware, "pathos das coisas", termo utilizado por Motoori Norinaga ${ }^{112}$ para definir uma das principais características das obras da época Heian como Genji Monogatari, cujas personagens se destacavam pela sua elegância e apurado senso estético.

As narrativas setsuwa de Konjaku Monogatarishû apresentam atributos diversos dessa estética vigente, na medida em que o foco passa a ser o mundo multifacetado, no qual uma variedade de personagens vem se somar, reproduzindo o mundo em transformação que se vivia na época. O lutador de sumô é uma delas. Protagonista de um dos importantes eventos anuais da corte, os lutadores são originários das províncias, diferentemente das personagens nobres de grande parte das narrativas de Heian e, como tal, são identificados através de suas ações, seus trajes ou seu modo de vida. Tendo como espectadores a nobreza de Heian e até mesmo o imperador, o que se espera de sua performance é totalmente diverso dos elegantes encontros amorosos ou os refinados entretenimentos como os encontros poéticos, sessões musicais ou bailados da nobreza. Para serem reconhecidos e aclamados, os lutadores precisavam mostrar sua agilidade, técnica e principalmente a sua força para derrotar seus adversários.

Konjaku Monogatarishû dá destaque à característica mais evidente dos lutadores, que é a sua força descomunal, caso de Narimura e Tsuneyo da narrativa 25, que realizam uma violenta disputa. A força dos lutadores é também descrita de forma hiperbólica como nas narrativas 22 e 23 , onde lutadores enfrentam e vencem de forma espetacular uma serpente gigante que mede forças com Tsuneyo e acaba morrendo, partindo-se em dois, ou Munehira, que enfrenta um tubarão e, levantando-o, atira-o para longe e derrota um representante da própria Natureza. Por outro lado, as narrativas 21 e 24, embora façam referências aos lutadores Narimura e Mitsutô, mostram que nem sempre os lutadores são invencíveis, podendo ser derrotados por

112 Motoori Norinaga 本居宣長 (1730-1801) - estudioso da Literatura Clássica Japonesa tem importantes contribuições no estabelecimento da crítica literária de clássicos como Genji Monogatari e Man'yôshû. 
um franzino estudante, caso de Narimura, ou que possuem uma irmã ainda mais forte que o próprio lutador, caso de Mitsutô.

Confirmando uma das características do setsuwa apontadas por Nishio Kôichi ${ }^{113}$, que ressalta a ênfase dos fatos e acontecimentos que se destacam por sua singularidade e o estilo dinâmico e objetivo, podemos ver que as referidas narrativas setsuwa surpreendem por apresentarem diversos aspectos sobre o tema do sumô, enfatizando que no mundo do setsuwa, assim como na vida, nem sempre as regras são seguidas, mas muitas vezes, quebradas. Assim, existem os lutadores renomados cuja força descomunal pode vencer animais monstruosos, mas eles podem também ser vencidos por um estudante franzino ou uma frágil mulher.

\section{REFERÊNCIAS BIBLIOGRÁFICAS}

CUYLER. P. L. Sumo: From Rite to Sport. 3a. reimpressão. New York\&Tokyo: Weatherhill, 1991.

KOMINE, Kazuaki (org.). Konjaku Monogatarishû wo Manabu Hitono Tameni (Para os Pesquisadores sobre Konjaku Monogatarishû). 1a. edição. Kyoto: Sekai Shisôsha, 2003.

MABUCHI, Kazuo e outros. Konjaku Monogatarishû 3. Coleção Nihon Koten Bungaku Zenshû 23. 4a. edição. Tokyo: Shôgakukan, 1974.

MAGARA, Hiroshi. Kawazugake ni tsuite (Sobre o Golpe Kawazugake). Disponível em $<$ https:// core.ac.uk/download/pdf/59282438.pdf> Acesso em: 11/04/2018.

NAGANO, Jôichi. Konjaku Monogatarishû no Kanshô to Hihyô (Apreciação e Crítica sobre Konjaku Monogatarishû). 1'. edição. Tokyo: Meiji Shoin, 1978.

NISHIO, Koichi. "Setsuwa to Setsuwa Bungaku" (Setsuwa e Literatura Setsuwa). Kokugo to Kokubungaku. Tokyo, Shibundô, 52(9), p. 1-12, setembro de 1975.

NITTA, Ichirô. Sumô: Sono Rekishi to Gihô (Sumô: História e Técnicas). 1a. edição. Tokyo: Nihon Budôkan, 2016.

Sumô no Rekishi (História do Sumô). 1ª edição. Tokyo: Yamakawa Shuppansha, 1994.

OINUMA, Yoshihiro. Nihon Shakai ni okeru Sumô no Rekishi (A História do Sumô na Sociedade Japonesa). Disponível em: <https:ci.nii.ac.jp/els/contents110000194851.pdf?i$\mathrm{d}=$ ART0000561878 > Acesso em 10/07/2018.

SAKAKURA, Atsuyoshi e outros. Konjaku Monogatarishû: Honchô Sezokubu Ichi. (Konjaku Monogatarishû: narrativas Seculares do Japão 1). Coleção Shinchô Nihon Koten Shûsei 16. 1a. edição. Tokyo, Shinchôsha, 1978.

SARGEANT, J. A. Sumo: the sport and the tradition. 1a. edição. Vermont\&Tokyo: Charles E. Tuttle Company, 1959.

113 Cf. NISHIO, Koichi. “Setsuwa to Setsuwa Bungaku”. Kokugo to Kokubungaku. Tokyo, Shibundô, setembro de 1975, p. 1-12. 
SHIMOYACHI, Katsutoshi. Chûsei no Sumô ni kansuru Ikkôsatsu: Sumai no Sechi Haizetsugo no Sumaibito no Yukue (Considerações sobre o Sumô da Idade Média Japonesa: o Destino dos Lutadores após o Fim do Festival Anual de Sumô). Disponível em $<$ http:repo. komazawa-u.ac.jp/opac/repositor/all/30196/jsb05-1-03.pdf> Acesso em 11/07/2018.

WAKAYAMA, Moritarô. Sumô Ima Mukashi (Sumô: Agora e Passado). 1a. edição. Tokyo: Kawade Shobô Shinsha, 1963.

YAMADA, Tomoko. Sechie Zumôkô (Festival Sazonal de Sumô). Disponível em $<$ https:// echolab.ddo.jp/Libraries/大谷学報64巻第2/大谷学報64巻第2号003山田知子「節会相撲 孝」.pdf> Acesso em: 11/04/2018.

YOSHIZAKI, Shoji e INANO, Kazuhiko. Sumô ni okeru Nyonin Kinsei no Dentô (Sobre a Tradição da Proibição de Mulheres no Sumô). Disponível em <http:s-ir.sap.hokkyodai. ac.jp/dspace/handle/123456789/933> Acesso em 11/04/2018. 